\title{
PENENTUAN KEBIJAKAN PERSEDIAAN DAN DISTRIBUSI PAKAN TERNAK SAPI YANG OPTIMAL DENGAN MENGGUNAKAN MODEL IDQ DAN DWP
}

\author{
Frank Al Imam Passauri Gunawan Madyono Putro \\ Fakultas Teknologi Industri, Program Studi Teknik Industri Jurusan Teknik Industri Universitas \\ pembangunan Nasional "Veteran" Yogyakarta Jl. Babarsari 2 Tambakbayan, Yogyakarta, \\ 55281Telp. (0274) 485363 Fak : (0274) 486256
}

\begin{abstract}
ABSTRAK
Koperasi Jasa Usaha Bersama (KJUB) Puspetasari merupakan salah satu produsen pakan ternak di daerah Jawa Tengah yang berlokasi di Jalan Stasiun nomor 1, Klepu, Ceper, Klaten. Pakan ternak dengan merk dagang Nutrifeed yang diproduksi oleh KJUB terdiri dari enam macam varian yaitu DC 131, DC 132, DC 133, BC 131, BC 132, dan BC 133. Selama ini KJUB dalam mendistribusikan produknya adalah dengan mengirimkan setiap hasil produksi langsung ke distributor. Akan tetapi, kapasitas gudang distributor terbatas sehingga produk yang dikirim oleh KJUB kembali lagi karena gudang distributor penuh. Akibat yang ditimbulkan adalah KJUB terpaksa berhenti berproduksi untuk sementara waktu karena harus menunggu produk terjual terlebih dahulu agar persediaan digudang KJUB bisa di distribusikan dan ditampung olah pihak distributor. Kondisi ini tentunya berdampak tidak baik bagi KJUB karena mereka akan mengalami kerugian waktu, kerugian materi, dll. Untuk itu diperlukan kebijakan-kebijakan tentang produksi dan persediaan yang bertujuan untuk meminimalkan total biaya gabungan antara KJUB dan distributornya.

Dalam penelitian ini digunakan model Identical delivery quantity (IDQ) dan Delivery what produced (DWP).Model IDQ Merupakan kebijakan dimana jumlah pengiriman kepada distributor adalah sama pada setiap pengirimannya atau jumlah pengiriman sesuai dengan jumlah yang diminta. Persediaan yang ada dari produksi tidak dikirim ke distributor. Sedangkan model DWP merupakan metode yang sama untuk mencari total biaya gabungan antara perusahaan dan distributornya akan tetapi jumlah produk yang dikirim tidaklah selalu sama. Semua persediaan dari produksi yang ada dikirim langsung kepada distributor. Pengolahan data dilakukan dengan tiga tahap. Pertama menghitung jumlah total biaya gabungan dengan menggunakan model $I D Q$, kedua menghitung jumlah total biaya gabungan dengan menggunakan model DWP, dan ketiga mencari rasio perbandingan antara model IDQ dan DWP.

Hasil penelitian menunjukkan bahwa model DWP lebih baik daripada model IDQ maupun dengan sistem yang digunakan oleh KJUB saat ini yaitu dengan selisih 22,19\%. Sehingga KJUB sebaiknya menggunakan model DWP dalam mendistribusikan produknya untuk meminimalkan biaya. Dari strategi yang telah dipilih dapat ditentukan suatu kebijakan dalam melakukan produksi dan distribus yang optimal.
\end{abstract}

Kata kunci: Pakan ternak, Persediaan, Distribusi, Identical delivery quantity, Deliviery what produced.

\section{PENDAHULUAN}

Persediaan sangat penting bagi suatu perusahaan, baik persediaan bahan baku maupun persediaan yang berupa produk jadi. Persediaan sangat menentukan kelangsungan hidup suatu perusahaan. Persediaan yang baik adalah persediaan yang tidak terlalu besar ataupun terlalu sedikit. Jumlah persediaan yang besar akan menimbulkan biaya penyimpanan yang besar pula sehingga keuntungan menjadi berkurang. Selain itu, barang yang disimpan juga bisa rusak jika tidak disimpan dengan baik. Sebaliknya, jika jumlah persediaan terlalu sedikit maka akan terjadi kekurangan barang yang dijual kepada konsumen. Hal ini tentunya tidak diinginkan oleh perusahaan dalam bisnis mereka. Oleh sebab itu persediaan harus diperhatikan dan direncanakan dengan sebaik mungkin agar perusahaan tidak mengalami kerugian seperti kerugian waktu, materi, dan tenaga kerja.

Koperasi Jasa Usaha Bersama (KJUB) Puspetasari merupakan salah satu produsen pakan ternak di daerah Jawa Tengah yang berlokasi di Jalan Stasiun nomor 1, Klepu, Ceper, Klaten. Pakan ternak dengan merk dagang Nutrifeed yang diproduksi oleh KJUB terdiri dari enam macam varian yaitu DC 131, 
DC 132, DC 133, BC 131, BC 132, dan BC 133.

Konsumen dari produk tersebut adalah peternak-peternak Sapi seperti Sapi potong dan Sapi perah. KJUB memiliki distributor yang terdapat di daerah Pati untuk memasarkan produknya. Distributor ini juga merupakan unit bagian dari KJUB tersebut. Distributor tersebut juga bisa dikatakan seperti gudang untuk produk jadi yang akan dipasarkan untuk sekitar daerah tersebut. KJUB memproduksi produknya secara kontinyu dengan jumlah produksi yang telah ditentukan. Selama ini KJUB dalam mendistribusikan produknya adalah dengan mengirimkan setiap hasil produksi langsung ke distributor. Akan tetapi, kapasitas gudang distributor terbatas sehingga produk yang dikirim oleh KJUB kembali lagi karena gudang distributor penuh. Akibat yang ditimbulkan adalah KJUB terpaksa berhenti berproduksi untuk sementara waktu karena harus menunggu produk terjual terlebih dahulu agar persediaan digudang KJUB bisa di distribusikan dan ditampung olah pihak distrubutor. Kondisi ini tentunya berdampak tidak baik bagi KJUB karena mereka akan mengalami kerugian waktu, kerugian materi, dll. Untuk itu diperlukan kebijakan-kebijakan tentang produksi dan persediaan yang bertujuan untuk meminimalkan total biaya gabungan antara KJUB dan distributornya.

Ada cara yang dapat digunakan untuk mengintegraksikan persediaan di kedua unit bisnis tersebut yaitu dangan menggunakan model Identical Delivery Quantity (IDQ) dan Delivery What Produced (DWP). model IDQ merupakan kebijakan dimana jumlah pengiriman kepada distributor adalah sama pada setiap pengirimannya atau jumlah pengiriman sesuai dengan jumlah yang diminta. Persediaan yang ada dari produksi tidak dikirim ke distributor. Sedangkan model DWP merupakan metode yang sama untuk mencari total biaya gabungan antara perusahaan dan distributornya akan tetapi jumlah produk yang dikirim tidaklah selalu sama. Semua persediaan dari produksi yang ada dikirim langsung kepada distributor.

\section{METODE PENELITIAN}

\section{Rumusan Masalah}

Bagaimana mengetahui perbandingan biaya persediaan yang dilakukan oleh KJUB saat ini dengan biaya persediaan menggunakan IDQ dan DWP

\section{Tujan Penelitian}

Menghitung selisih total biaya gabungan antara model DQ dan DWP yang diusulkan dengan strategi yang digunakan KJUB saat ini. yang diusulkan dengan strategi yang digunakan KJUB saat ini.

\section{Kerangka penelitian}

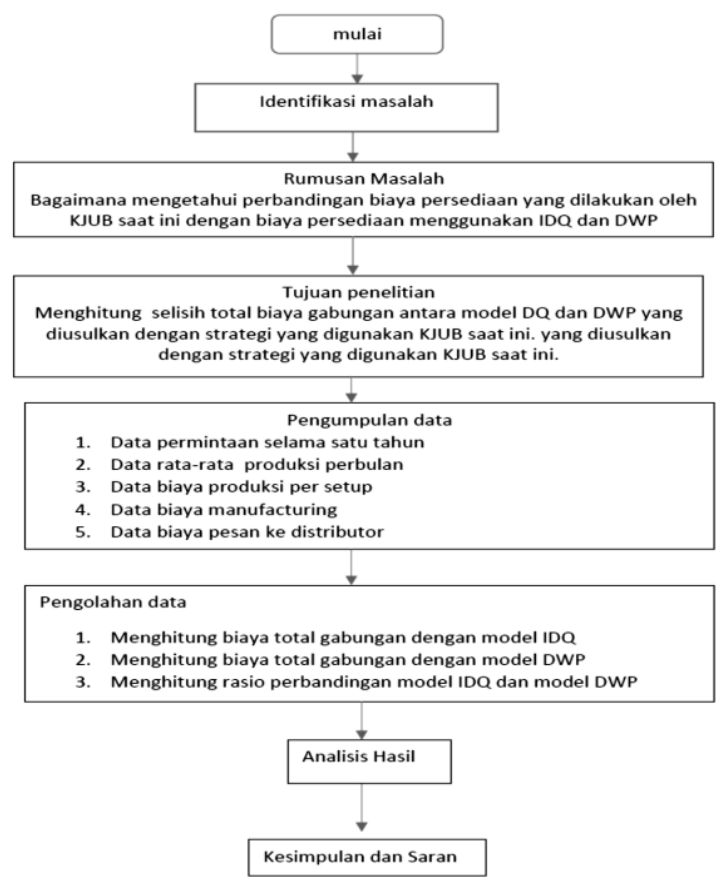

Gambar 1. Kerangka penelitian

\section{HASIL DAN PEMBAHASAN}

\section{Data pengamatan}

Data diperoleh berdasarkan data permintaan produk BC 133 tahun 2014 dari bulan Januari sampai Desember. 
Adapun data yang diperoleh adalah sebagai berikut:

a. Data Permintaan BC 133.

Tabel 1. Data permintaan

\begin{tabular}{|l|c|}
\hline \multicolumn{1}{|c|}{ Bulan } & Jumlah (Karung) \\
\hline Januari & 13.780 \\
\hline Februari & 14.485 \\
\hline Maret & 14.871 \\
\hline April & 15.419 \\
\hline Mei & 17.321 \\
\hline Juni & 16.098 \\
\hline Juli & 15.396 \\
\hline Agustus & 14.379 \\
\hline September & 19.053 \\
\hline Oktober & 16.517 \\
\hline November & 20.339 \\
\hline Desember & 21.059 \\
\hline
\end{tabular}

b. Harga beli produk: Rp. 100.000/karung

c. Kapasitas gudang: 30.000 karung

d. perkiraan biaya penyimpanan dari modal yang ditanamkan dalam prosentase: 0,12/karung/tahun

e. Biaya produksi per set up: Rp. 135.000/set up

f. Biaya manufacturing pada perusahaan: Rp. 90.000

g. Biaya pesanan pada distributor: Rp. 95.000/pesan

h. Rata-rata produksi: 23.000 karung/bulan

\section{Pengolahan Data}

a. Menghitung biaya persediaan

Biaya persediaan pada perusahaan

$\left(\mathrm{H}_{\mathrm{v}}\right)$ adalah Rp. $740 /$ karung/bulan

Biaya persediaan pada distributor

$\left(\mathrm{H}_{\mathrm{b}}\right)$ Rp. 1.000/karung/bulan

1) Perbandingan biaya pesan dan biaya set up

Perbandingan antara biaya pesan dan biaya set up adalah sebagai berikut:

$$
\begin{gathered}
\propto=\frac{\text { biaya pesan }(A)}{\text { biaya set up }(S)}=\frac{R p \cdot 95 \cdot 000}{R p \cdot 135.000} \\
=0,70
\end{gathered}
$$

2) Perbandingan biaya penyimpanan persediaan

Perbandingan antara biaya simpan pada perusahaan dan biaya simpan pada distributor adalah sebagai berikut:

$$
\beta=\frac{H_{b}}{H_{v}}=\frac{R p \cdot 1 \cdot 000}{R p \cdot 740}=1,35
$$

3) Perbandingan antara permintaan dan rata-rata produksi Perbandingan antara permintaan perbulan dan rata-rata produksi setiap bulan selama setahun dari bulan Januari - Desember.

$$
\begin{gathered}
\gamma=\frac{\text { jumlah permintaan per bulan }}{\text { rata }- \text { rata produksi per bulan }} \\
=\frac{13.780}{23.000}=0,6
\end{gathered}
$$

\section{b. Identical delivery quantity (IDQ)}

Adapun perhitungan biaya total gabungan dengan model IDQ adalah sebagai berikut:

\section{Production run $(\mathrm{Q})$}

Rumus untuk menghitung Production run adalah sebagai berikut:

$$
\mathrm{Q}=\sqrt{\frac{2 D(A+S)}{\left(H_{b}-H_{V}\right)+H_{V}\left(1+\frac{D}{P}\right)}}
$$

Contoh Production run pada bulan Januari:

$$
\begin{aligned}
& Q=\sqrt{\frac{2 \times 13.780(95.000+135.000)}{(1.000-740)+740\left(1+\frac{13.780}{23.000}\right)}} \\
& =2.095,64 \text { karung }
\end{aligned}
$$

Perhitungan biaya total gabungan perhitungan model IDQ pada bulan Januari adalah:

$$
Z^{*}(I D Q)=\sqrt{2 \times 13.780 \times 135.000 \times 740}
$$


$=1.659 .290,21 \times 1,79$

$=R p \cdot 2.970 .129,48$

Berikut ini adalah hasil perhitungan selengkapnya untuk

Tabel 2. Biaya total gabungan model IDQ

\begin{tabular}{|c|c|c|c|c|c|}
\hline Bulan & $\begin{array}{c}\text { D } \\
\text { (karung }\end{array}$ & $\begin{array}{c}\text { Q } \\
\text { (karung) }\end{array}$ & $\gamma$ & $\mathbf{k}_{\mathbf{1}}$ & $\mathbf{Z}^{*}$ \\
\hline \hline Januari & 13.780 & $2.095,64$ & 0,60 & 5 & Rp. 2.970.129,48 \\
\hline Februari & 14.485 & $2.131,89$ & 0,63 & 4 & Rp. 2.909.062,84 \\
\hline Maret & 14.871 & $2.151,02$ & 0,63 & 4 & Rp. 2.947.568,71 \\
\hline April & 15.419 & $2.177,35$ & 0,67 & 4 & Rp. 2.966.282,78 \\
\hline Mei & 17.321 & $2.261,95$ & 0,75 & 5 & Rp. 3.106.709,83 \\
\hline Juni & 16.098 & $2.208,70$ & 0,70 & 4 & Rp. 2.995.023,07 \\
\hline Juli & 15.396 & $2.176,26$ & 0,67 & 4 & Rp. 2.964.069,61 \\
\hline Agustus & 14.379 & $2.126,55$ & 0,63 & 5 & Rp. 2.983.147,68 \\
\hline September & 19.053 & $2.330,99$ & 0,83 & 4 & Rp. 3.121.759,26 \\
\hline Oktober & 16.517 & $2.227,39$ & 0,72 & 5 & Rp. 3.070.082,39 \\
\hline November & 20.339 & $2.378,07$ & 0,88 & 4 & Rp. 3.164.916,04 \\
\hline Desember & 21.059 & $2.403,03$ & 0,92 & 4 & Rp. 3.158.910,60 \\
\hline
\end{tabular}

c. Delivery what proced (DWP)

Adapun perhitungan biaya total gabungan dengan model IDQ adalah sebagai berikut:

1) Production run (Q)

Production run pada bulan Januari minggu pertama

$$
\text { Q }
$$

$$
\sqrt{\frac{2 \times 2.700(95.000+135.000)}{(1.000-740)+740\left(1+\frac{2.700}{23.000}\right)}}=1.068,99
$$

karung

2) Biaya total gabungan model DWP

Perhitungan biaya total gabungan untuk model DWP bulan Januari pada $\mathrm{k}_{2=1}$ adalah:

$Z^{*}(D W P)=\sqrt{2 \times 13.780 \times 135.000 \times 740}$

$$
\begin{aligned}
& \sqrt{\frac{(1,35+0,60)(1-060)\left(1+0,60^{1}\right)(1+1 \times 0,70)}{(1+0,60)\left(1-0,60^{1}\right)}} \\
& =R p \cdot 3 \cdot 019.908,18
\end{aligned}
$$

biaya total gabungan perhitungan model IDQ dari bulan JanuariDesember 
Tabel 3. Biaya total gabungan model DWP

\begin{tabular}{|c|c|c|c|c|c|c|c|c|}
\hline Bulan & $\begin{array}{c}\mathrm{D} \\
\text { (karung) }\end{array}$ & $\begin{array}{l}\text { Min } \\
\text { ggu }\end{array}$ & $\begin{array}{c}\mathbf{Q} \\
\text { (karung) }\end{array}$ & $\gamma$ & $\mathbf{N}$ & $\overline{K_{2}}$ & $\mathrm{Z}^{*} \mathrm{DWP}$ & $\mathbf{Z}^{*}$ Min \\
\hline \multirow{5}{*}{$\begin{array}{c}\text { Januar } \\
\mathrm{i}\end{array}$} & \multirow{8}{*}{13.780} & 1 & $1.068,99$ & \multirow{8}{*}{0,60} & \multirow{8}{*}{$\begin{array}{c}1,6 \\
7\end{array}$} & 1 & Rp. $3.019 .908,18$ & \multirow{8}{*}{ Rp. $2.538 .714,02$} \\
\hline & & 2 & $1.091,26$ & & & 2 & Rp. $2.621 .678,53$ & \\
\hline & & 3 & $1.086,99$ & & & 3 & Rp. $2.538 .714,02$ & \\
\hline & & 4 & $1.084,49$ & & & 4 & Rp. 2.571.899,83 & \\
\hline & & 5 & $1.063,51$ & & & 5 & Rp. $2.654 .864,34$ & \\
\hline \multirow{3}{*}{$\begin{array}{l}\text { Dese } \\
\text { mber }\end{array}$} & & & & & & & & \\
\hline & & & & & & & & \\
\hline & & & & & & & & \\
\hline
\end{tabular}

d. Menghitung rasio perbandingan biaya model IDQ dan DWP

Dari biaya yang didapat dari masing-masing model akan dibandingkan untuk mengetahui strategi terbaik, perhitungan rasio dirumuskan sebagai berikut:

$$
R=\frac{Z^{*}(I D Q)}{Z^{*}(D W P)} \times 100 \%
$$

Adapun hasil perbandingan atau rasio dari kedua model untuk bulan Januari adalah:

$$
\begin{gathered}
R=\frac{R p \cdot 2 \cdot 970 \cdot 129,48}{R p \cdot 2 \cdot 538 \cdot 714,02} \times 100 \% \\
=116,99 \%
\end{gathered}
$$

Berikut ini adalah hasil perbandingan biaya total gabungan antara IDQ dan DWP

Tabel 4. Rasio perbandingan biaya total gabungan antara IDQ dan DWP

\begin{tabular}{|c|c|c|c|c|}
\hline Bulan & $\begin{array}{c}\text { D } \\
\text { (katung) }\end{array}$ & IDQ & DWP & R(\%) \\
\hline \hline Januari & 13.780 & Rp. 2.970.129,48 & Rp. 2.538.714,02 & $116,99 \%$ \\
\hline Februari & 14.485 & Rp. 2.909.062,84 & Rp. 2.585.833,64 & $112,50 \%$ \\
\hline Maret & 14.871 & Rp. 2.947.568,71 & Rp. 2.620.061,07 & $112,50 \%$ \\
\hline April & 15.419 & Rp. 2.966.282,78 & Rp. 2.650.347,33 & $111,92 \%$ \\
\hline Mei & 17.321 & Rp. 3.106.709,83 & Rp. 2.734.648,78 & $113,61 \%$ \\
\hline Juni & 16.098 & Rp. 2.995.023,07 & Rp. 2.690.140,49 & $111,33 \%$ \\
\hline Juli & 15.396 & Rp. 2.964.069,61 & Rp. 2.648.369,88 & $111,92 \%$ \\
\hline Agustus & 14.379 & Rp. 2.983.147,68 & Rp. 2.576.354,81 & $115,79 \%$ \\
\hline September & 19.053 & Rp. 3.121.759,26 & Rp. 2.868.116,32 & $108,84 \%$ \\
\hline Oktober & 16.517 & Rp. 3.070.082,39 & Rp. 2.706.759,03 & $113,42 \%$ \\
\hline November & 20.339 & Rp. 3.164.916,04 & Rp. 2.963.329,03 & $106,80 \%$ \\
\hline Desember & 21.059 & Rp. 3.158.910,60 & Rp. 3.015.323.76 & $104,76 \%$ \\
\hline
\end{tabular}




\section{Analisis Hasil Penelitian}

Berdasarkan hasil pengolahan data seperti pada tabel 4.11 tersebut maka KJUB sebaiknya menggunakan model DWP dalam mendistribusikan produknya, karena biaya yang dikeluarkan lebih rendah jika dibandingkan dengan biaya total gabungan yang dikeluarkan KJUB dengan sistem yang mereka gunakan sekarang. Berikut perbandingan total biaya gabungan antara model DWP dengan sistem yang digunkan oleh KJUB.

Tabel 5. Perbandingan biaya total gabungan DWP dan sistem KJUB

\begin{tabular}{|l||c|c|}
\hline \multicolumn{1}{|c|}{ Bulan } & Sistem KJUB & DWP \\
\hline \hline Januari & Rp. 3.117 .600 & Rp. $2.538 .714,02$ \\
\hline Februari & Rp. 3.194 .100 & Rp. $2.585 .833,64$ \\
\hline Maret & Rp. 3.194 .100 & Rp. 2.620.061,07 \\
\hline April & Rp. 3.194 .100 & Rp. $2.650 .347,33$ \\
\hline Mei & Rp. 3.117 .600 & Rp. 2.734.648,78 \\
\hline Juni & Rp. 3.194.100 & Rp. 2.690.140,49 \\
\hline Juli & Rp. 3.194.100 & Rp. 2.648.369,88 \\
\hline Agustus & Rp. 3.117.600 & Rp. 2.576.354,81 \\
\hline September & Rp. 3.194.100 & Rp. 2.868.116,32 \\
\hline Oktober & Rp. 3.117.600 & Rp. 2.706.759,03 \\
\hline November & Rp. 3.194.100 & Rp. 2.963.329,03 \\
\hline Desember & Rp. 3.194.100 & Rp. 3.015.323.76 \\
\hline \hline Total & Rp. 38.023.200 & Rp. 29.582.674,40 \\
\hline \hline Selisih & \multicolumn{2}{|c|}{ Rp. 8.440.525,60 } \\
\hline
\end{tabular}

Berikut ini adalah grafik perbandingan biaya total gabungan antara model DWP dengan sistem yang digunakan KJUB:

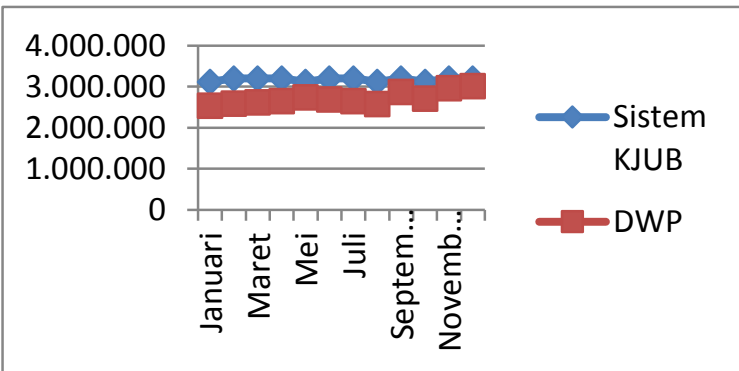

Gambar 2. Grafik perbandingan biaya total gabungan antara model DWP dengan sistem yang digunakan KJUB
Dari langkah distribusi yang telah dipilih tersebut dapat dibuat kebijakan produksi dan distribusi yang optimal yang disajikan ditabel 4.14, 4.15, 4.16.

\section{KESIMPULAN}

Berdasarkan pengolahan data dan pembahasan yang telah dilakukan, maka dapat ditarik kesimpulan sebagai berikut: 1. Total biaya gabungan dengan menggunakan model DWP lebih rendah jika dibandingkan dengan biaya yang dikeluarkan oleh KJUB dengan sistem yang mereka gunakan sekarang dalam mendistribusikan produk pakan ternak Sapi BC 133. 
2. Selisih total biaya gabungan dengan model DWP dengan sistem yang digunakan KJUB sekarang adalah Rp. $8.440 .525,60$ atau sebesar 22,19\%.

\section{DAFTAR PUSTAKA}

Assauri, S., 2004, Manajemen Produksi dan Operasi, Edisi Revisi, Lembaga

Universitas Indonesia.

Penerbit Fakultas Ekonomi

Gaspersz, Vincent., 2005, Production Planning and Inventory Control Berdasarkan

Pendekatan Sistem Terintegrasi MRP II dan JIT Menuju Manufacturing 21, Jakarta, PT.Gramedia Pustaka Utama.

Hernawan, J., 2007, Kombinasi Strategi Distribusi Untuk Menurunkan Biaya

Logistik. Jurnal Teknologi Industri,UAJY,Vol.XI.no.2:163172.

Rangkuti, F., 2004. Manajemen Persediaan: Aplikasi di Bidang Bisnis, Jakarta, Raja Grafindo Persada.

Ristono, A., 2009, Manajemen Persediaan, Yogyakarta, Graha Ilmu.

Sutapa, N., Fransiska., 2000, Model Matematis Persediaan Terintegras Antara Suatu Perusahaan dan Distributornya. Jurnal Teknik Industri, Universitas Kristen Petra, Vol.2, No.1:13-21.
Tersine, R., 1994, Principles of Inventory and Material Management, Prentice- Hall, New Jersey. 
